Parte IV

INTERFACE ENTRE OS CAPÍTULOS 



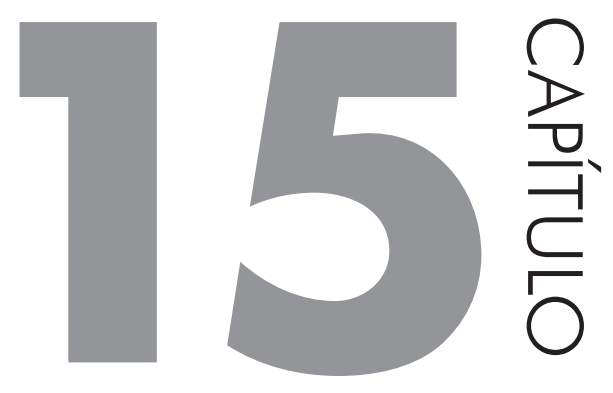

\section{O QUE FICOU da síntese aos caminhos}

\section{OTACILIO ANTUNES SANTANA}

\section{REVISITANDO O CONCEITO: "TUTOR"}

"Tutor do latim tutari, aquele que põe em segurança, protege, defende, guarda e tutela", a religar esse conceito enciclopédico a tudo o que foi perpassado, dos dados formais a sensibilidade do caminho, até a designação de 'fantasma' no prefácio, o Tutor é um ser pedagógico difícil de ser delimitado por conceitos, por sua grandeza entre o sistema educacional e o aluno UAB. O Tutor instiga a crítica e a emancipação (FREIRE, 2009), aproxima afeto ao intelecto (VIGOTSKY, 1989), é um interlocutor de um diálogo polifônico (BAKUNIN, 1988), e "verifica fatos" na era da Pós-Verdade (SUITER, 2016).

Se por um lado, a coreografia institucional não o permite um caminho viscoso, pela falta de um reconhecimento legal sem ambiguidades, por outro, a capacidade amorfa de adaptação e criatividade frente aos obstáculos o faz apetente, maior do que sua competência, e é isso que faz a diferença no Processo da Tutoria do Sistema da Universidade Aberta do Brasil, a manutenção de uma Zona de Desenvolvimento Proximal potencial e potente mesmo que dentro da Cultura Digital Ambivalente.

\section{QUO VADIS}

"Tudo em que se refere a Tutoria e a Universidade Aberta do Brasil deve sair do status de Projeto, para se tornar Programa dentro das Universidades e do Mi- 
nistério da Educação...”, palavras da Prof ${ }^{a}$. Cacilda Andrade, nas quais rebatem sob nós o compromisso da defesa dessa função e instituição frente as naturais instabilidades governamentais. Valorizar o Tutor, relacionar com ele de forma horizontal, ter co-autorias e co-pesquisas, serão os pontos fundamentais na relação Professor-Tutor.

Mas, para alimentar um futuro programa, se conseguiria formar Tutores Profissionais? Há pelo visto nos capítulos anteriores uma especificidade na atuação do Tutor: $1 / 3$ com conhecimento sobre tecnologia digital de informação e comunicação e educação a distância, 1/3 com conhecimento sobre Gestão Organizacional, e 1/3 com conhecimento específico sobre cada área (e.g. Geografia) (Figura 15.1). Com essa gênese epistemológica e um possível ontologismo na atuação Tutor, poderia se criar um curso de licenciatura ou de um mestrado profissional em "Tutoria para a Educação a Distância”. Não só para atuar no Sistema da Universidade Aberta do Brasil, e também em instituições Privadas, ou em plataformas de Curso Online Aberto e Massivo (MOOC) em que há possibilidade de formação por investimento financeiro particular.

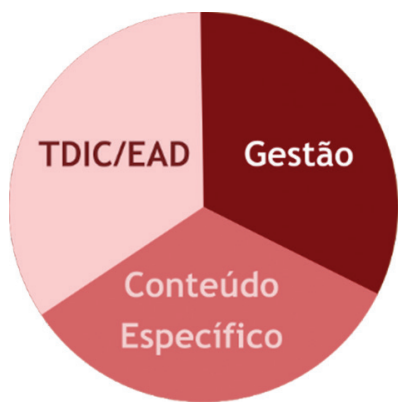

Figura 15.1. Dimensão Curricular de uma Licenciatura ou de um Mestrado Profissional em Tutoria para Educação a Distância.

\section{REFERÊNCIAS}

BAKUNIN, M. A. Deus e o estado. São Paulo, SP: Cortez, 1988. 97 p.

FREIRE, P. Educação como prática da liberdade. São Paulo: Paz e Terra, 2009.158 p.

SUITER, J. Post-truth Politics. Political Insight, v. 7, n. 3, p. 25-27, 2016. DOI: 10.1177/2041905816680417

VIGOTSKY, L. S. A formação social da mente: o desenvolvimento dos processos psicológicos superiores. 3. ed. São Paulo: Martins Fontes, 1989. 168 p. 


\section{GLOSSÁRIO}

Ambiente Virtual de Aprendizagem I AVA I Moodle $\rightarrow$ é um sistema de gerenciamento de aprendizagem em que o mediador pode depositar recursos didáticos, ter interações síncronas (chats/webconferências) e assíncronas (fóruns), instrumentalizar avaliações e feedbacks, e, emitir relatórios avaliativos, além de executar plug-ins diversos (e.g. softwares estatísticos).

Atribuição $\longrightarrow$ é a responsabilidade e competência própria de um cargo ou função; é a mínima prerrogativa funcional exigida (e.g. ser assíduo).

Autodisciplina $\longrightarrow$ é a capacidade de se impor disciplina. No caso acadêmico, pode ser a capacidade de gerir o tempo e as atividades a serem executadas nesse período.

Autonomia $\longrightarrow$ é a capacidade da vontade humana de se autodeterminar segundo uma legislação moral por ela mesma estabelecida, livre de qualquer fator estranho ou exógeno com uma influência subjugante, tal como uma inclinação ideológica coercitiva.

Avatar $\longrightarrow$ é o sujeito metafórico criado com uma semiótica e figurino para um determinado cenário (e.g. Ambiente Virtual de Aprendizagem). Ele pode representar o ser real ou o ser ideal.

Consórcio $\mathrm{EaD} \longrightarrow$ é um grupo de empresas e/ou instituições autônomas que têm operações comuns e atuam em um mesmo projeto ou programa. No caso da $\mathrm{EaD}$, são instituições acadêmicas que se unem para disponibilizar cursos de graduação a distância em polos regionais.

Educação a Distância $\mid \mathrm{EaD} \longrightarrow$ é uma modalidade de educação mediada por técnicas e tecnologias em que discentes e docentes estão separados espacial e/ ou temporalmente, ou seja, não estão fisicamente presentes em um ambiente presencial de ensino-aprendizagem.

Educometria $\longrightarrow$ é o método de mensuração das variáveis relacionadas ao processo de ensino e aprendizagem conjugado com interpretações qualitativas, sensíveis e sociais. É a interface entre a análise quantitativa e qualitativa na área do conhecimento da Educação que emerge uma síntese.

e-Tutoria I Tutoria $\mathrm{EaD} \longrightarrow$ é um processo no qual envolve todos os atores e cenários institucionais da Educação a distância em que atue o Tutor executando suas atribuições. 
Eureca $\longrightarrow$ é uma exclamação que representa o momento exato da consolidação do conhecimento através da percepção de que resolveu o problema.

Evasão $\longrightarrow$ é o ato ou processo de decisão de abandono circunstancial ou planejado de um percurso acadêmico.

Formação $\longrightarrow$ é a construção de um conhecimento através da integração da teoria, prática e o sensível de um conteúdo, a permitir, a partir disso, a construção de hipóteses, novos métodos e novos arranjos teóricos.

Hibridismo na $\mathrm{EaD} \longrightarrow$ é um sistema ou método de ensino e aprendizagem que se utiliza, ou de maneira intervalar ou simultânea, a educação a distância e presencial, sem um predomínio ou exata proporção entre uma e outra modalidade.

Institucionalização $\longrightarrow$ ato ou efeito de fazer parte e ser reconhecido legalmente e legitimamente frente a uma instituição. No caso da $\mathrm{EaD}$, é fazer parte do estatuto dos institutos de ensino superior, bem como dos planos de desenvolvimento institucional, a valorizar seus atores, cenários e infraestruturas.

Interiorização $\longrightarrow$ é o ato ou efeito de ir a regiões ausentes da cobertura do ensino superior.

Mediação $\longrightarrow$ é o processo de interação de um elemento intermediário numa relação acadêmica (voluntárias, intencionais ou controladas), situado em um ambiente, socializado e com manuseio de objetos de aprendizagem que significam cognitivamente um sentido para um indivíduo e para seu coletivo.

Memória $\longrightarrow$ é uma capacidade natural que consiste em restabelecer e correlacionar experiências passadas com maior ou menor consciência de que a experiência do momento presente é um ato de revivificação.

Motivação $\longrightarrow$ é o motivo e o impulso interno que coloca o sujeito em ação.

Narrativa $\longrightarrow$ é a exposição de um acontecimento ou de uma série de acontecimentos mais ou menos encadeados, reais ou imaginários, por meio de palavras ou de imagens.

Ontologia $\longrightarrow$ é um conjunto de teorias, práticas ou sujeitos que por sua natureza, ideia, missão, função e valores, formam um ente.

Objeto Educacional $\longrightarrow$ é um recurso didático que complementa o arranjo para o caminho da construção de um conhecimento ou resolução de um problema de aprendizagem.

Paradigma $\longrightarrow$ é o modelo resultante de tendências conjecturais.

Poltergeist $\longrightarrow$ é um 'espírito' que causa espanto ou constante incômodo. Pode ser fantasioso ou real (e.g. problema familiar).

Práxis $\longrightarrow$ é a prática com sua reflexão, ou seja, a partir de uma prática a sua repetição necessariamente será diferente devido a reflexão causada pela anterior. 
Reflexão $\longrightarrow$ é a reavaliação sobre si próprio, suas representações, ideias e sentimentos.

Repositório $\rightarrow$ é um banco de dados que tem por objetivo armazenar, preservar, disseminar e possibilitar o acesso aberto, à produção científica, acadêmica, artística, técnica e administrativa de uma instituição acadêmica, bem como de seus indicadores de uso e satisfação.

SIG@ — é o Sistema de Informações e Gestão Acadêmica que apoia as áreas de ensino, pesquisa, recursos humanos, processos administrativos, planejamento institucional, gestão patrimonial, processo de eleição e gestão de restaurante universitário de uma Universidade.

Sincronia $\longrightarrow$ é o estado ou condição ou subjetivação de dois ou mais fenômenos ou fatos que ocorrem simultaneamente, relacionados entre si ou não. Assincronia se refere ao conceito de sincronia, porém em momento não simultâneos.

Tese I Hipótese I Antítese I Síntese $\rightarrow$ tese é a aceitação ou refutação de uma afirmação inicial (hipótese), que através da negação argumentada e contraposta do resultado (antítese), se chega a síntese que é a consideração final da hipótese pós reflexão de situações de aceitação e refutação da tese.

Sujeito $\longrightarrow$ é um ser que tem uma consciência e experiências únicas ou uma entidade que tem um relacionamento com outra entidade que existe fora de si mesma.

Superação $\longrightarrow$ é o ato ou efeito de superar; sobrepujamento.

Tecnologia da Informação e Comunicação I TIC I TDIC $\rightarrow$ são meios técnicos e um conjunto de recursos tecnológicos integrados entre si, que proporcionam, por meio das funções de hardware, software e peopleware, a automação e comunicação dos processos de ensino e aprendizagem.

Travessia I Caminho $\longrightarrow$ educação

Tutores a Distância $\longrightarrow$ é o sujeito que atua na Instituição de ensino executora, auxiliando o professor responsável pelo componente curricular no desenvolvimento de todas as atividades didático-pedagógicas programadas. Além disso, media a interação entre estudante e professor por meio das novas tecnologias de informação e comunicação adotadas pelo curso. Participa também das atividades presenciais, a saber, aulas e avaliações da aprendizagem nos polos.

Tutor Presencial $\longrightarrow$ é um orientador acadêmico com formação superior adequada que será responsável pelo atendimento dos estudantes nos polos municipais de apoio presencial e fará a interlocução entre os estudantes e às diversas instâncias administrativas do curso.

Universidade Aberta do Brasil $\longrightarrow$ é um programa articulador entre governo federal e entes federativos que apoia instituições públicas de ensino superior (IPES) a oferecerem cursos de nível superior e de pós-graduação por meio do uso da modalidade de educação a distância. 
Utopismo tecnológico $\longrightarrow$ se refere a qualquer ideologia baseada na crença de que os avances na ciências e tecnologia conduzirão a uma utopia, ou ao menos ajudarão a cumprir alguma ideia utópico.

Vivências $\longrightarrow$ é o ato de existir e um experiências de vida.

Zona de Desenvolvimento Proximal $\rightarrow$ é um espaço concreto ou abstrato de interação e socialização no qual o indivíduo e o coletivo a entorno aprender e ensinam de forma multimediada. 


\section{ÍNICE REMISSIVO}

Ambiente Virtual de Aprendizagem I AVA I Moodle, 07; 09; 22; 23; 26; 27; 28; $37 ; 45 ; 48 ; 49 ; 56 ; 59 ; 63 ; 66 ; 67 ; 69$; $70 ; 71 ; 80 ; 84 ; 85$

Atribuição, 07; 20; 24; 28; 29; 36; 37

Autodisciplina, 33; 58; 78

Autonomia, 23; 32; 33; 34; 35; 36; 53; $72 ; 78$

Avatar, 86

Consórcio EaD, 19

Educação a Distância I EaD, 09; 15; 16; $17 ; 18 ; 19 ; 20 ; 27 ; 30 ; 31 ; 33 ; 35 ; 36$; $43 ; 45 ; 51 ; 52 ; 53 ; 55 ; 60 ; 62 ; 63 ; 65$; $70 ; 71 ; 75 ; 77 ; 78 ; 79 ; 83 ; 84$

Educometria, 23

e-Tutoria I Tutoria EaD, 07; 09; 15; 17; 18; $20 ; 21 ; 22 ; 23 ; 24 ; 25 ; 26 ; 28 ; 29 ; 30$; $31 ; 35 ; 36 ; 37 ; 45 ; 47 ; 48 ; 49 ; 53 ; 55$; $58 ; 59 ; 61 ; 62 ; 63 ; 64 ; 65 ; 67 ; 69 ; 70$; 71; 75; 79; 80; 99; 100

Eureca, 07

Evasão, 33; 64; 66

Formação, 09; 10; 15; 17; 18; 20; 21; 23; $26 ; 30 ; 31 ; 32 ; 33 ; 35 ; 36 ; 52 ; 55 ; 56$; $58 ; 59 ; 61 ; 62 ; 63 ; 72 ; 78 ; 80 ; 83 ; 84$; $85 ; 93 ; 100$

Hibridismo na EaD, 16

Institucionalização, 09; 15; 16; 17; 19; 20

Interiorização, 53

Mediação, 21; 23; 27; 32; 36; 45; 63; 70; 71

Memória, 07; 09; 21; 22; 75; 80

Motivação, 28; 33; 34; 36; 57; 58
Narrativa, $07 ; 09 ; 15 ; 21 ; 22 ; 23 ; 27 ; 30 ; 37$; $48 ; 70 ; 80 ; 84 ; 91$

Ontologia, $07 ; 100$

Objeto Educacional, 83; 84; 93

Paradigma, 16; 19; 64

Poltergeist, 07

Práxis, 09; 22; 95

Reflexão, 17; 37; 64; 84; 85

Repositório, 85; 86; 95

SIG@, 23; 63

Sincronia, 70

Tese I Hipótese | Antítese I Síntese, 09; 10; 23; 26; 46; 95; 99

Sujeito, $07 ; 09 ; 15 ; 16 ; 18 ; 20 ; 30 ; 36 ; 43 ; 44$; $49 ; 70 ; 71 ; 72$

Superação, 22; 37; 47; 49; 56

Tecnologia da Informação e Comunicação | TIC I TDIC, 16; 25; 35; 47; 48; 56; 59; 63; 64; 72; 80

Travessia | Caminho, 07; 10; 18; 19; 22; 32; 56; 78; 83; 99

Tutores a Distância, 23; 24; 28; 37; 56

Tutor Presencial, 23; 24; 28; 47; 61

Universidade Aberta do Brasil, 07; 09; 16; $18 ; 19 ; 21 ; 36 ; 37 ; 65 ; 83 ; 86 ; 95 ; 99 ; 100$

Utopismo tecnológico, 07

Vivências, 15; 21; 27; 35; 41; 55; 72; 75; 84

Zona de Desenvolvimento Proximal, 22; 31; 58; 71; 99 